\title{
Control of Tensile Behavior of Ultra-High Performance Concrete Through Artificial Flaws and Fiber Hybridization
}

\author{
Su-Tae Kang ${ }^{1)}$, Kang-Seok Lee ${ }^{2)}$, Jeong-II Choi ${ }^{2)}$, Yun Lee $^{3)}$, Burak Felekoğlu ${ }^{4)}$, and \\ Bang Yeon Lee ${ }^{2), *}$ (1)
}

(Received March 21, 2016, Accepted May 25, 2016, Published online June 28, 2016)

\begin{abstract}
Ultra-high performance concrete (UHPC) is one of the most promising construction materials because it exhibits high performance, such as through high strength, high durability, and proper rheological properties. However, it has low tensile ductility compared with other normal strength grade high ductile fiber-reinforced cementitious composites. This paper presents an experimental study on the tensile behavior, including tensile ductility and crack patterns, of UHPC reinforced by hybrid steel and polyethylene fibers and incorporating plastic beads which have a very weak bond with a cementitious matrix. These beads behave as an artificial flaw under tensile loading. A series of experiments including density, compressive strength, and uniaxial tension tests were performed. Test results showed that the tensile behavior including tensile strain capacity and cracking pattern of UHPC investigated in this study can be controlled by fiber hybridization and artificial flaws.
\end{abstract}

Keywords: artificial flaw, crack pattern, fiber hybridization, tensile behavior, UHPC.

\section{Introduction}

Recent industrial demands for new and excellent construction materials promote the development of various kinds of advanced cementitious materials. One of them is ultra-high performance concrete (UHPC) having high strength, high durability, and good workability (Richard and Cheyrezy 1995; Schmidt and Fehling 2005), on which active research is still now being conducted. Association Française de Génie Civil recommendation on UHPC defines it as a material with a cement matrix of a characteristic compressive strength more than $150 \mathrm{MPa}$, and with sufficient fiber content to prevent brittle fracture behavior (AFGC 2002). Additionally, according to Federal Highway Administration (FHWA), it is defined as a cementitious composite material composed of an optimized gradation of granular constituents, a water-to-cementitious materials ratio of less than 0.25 , and a high percentage of discontinuous internal fiber reinforcement (Graybeal 2011). The mechanical properties

\footnotetext{
${ }^{1)}$ Department of Civil Engineering, Daegu University, Gyeongsan 38453, Korea.

${ }^{2)}$ School of Architecture, Chonnam National University, Gwangju 61186, Korea.

*Corresponding Author; E-mail: bylee@jnu.ac.kr

${ }^{3)}$ Department of Civil Engineering, Daejeon University, Daejeon 34520, Korea.

${ }^{4)}$ Department of Civil Engineering, Dokuz Eylul University, Izmir, Turkey.
}

Copyright $($ The Author(s) 2016. This article is published with open access at Springerlink.com of UHPC include compressive strength greater than $150 \mathrm{MPa}$ and sustained post-cracking tensile strength greater than $5 \mathrm{MPa}$. Compressive strength is influenced by the curing method. Therefore the UHPC definition may be limited to the condition that typical moisture curing at room temperature is applied to it. UHPC presents several advantages as mentioned above, but it also has some disadvantages. UHPC is sometimes compared with high ductile fiberreinforced cementitious composites at normal strength grade. According to previous research on it (Rokugo et al. 2007; Stang and Li 2004), UHPC exhibits less ductile behavior compared to high ductile fiber-reinforced normal strength grade cementitious composites when the same amount of fiber is incorporated. Typical UHPC contains $2 \mathrm{vol} \%$ of steel fibers, whereas high ductile fiber-reinforced normal strength grade cementitious composites presenting excellent tensile strain capacity of more than $2 \%$ includes PVA (polyvinyl alcohol) or PE (polyethylene) fibers in general (Choi et al. 2016a, b; Lee et al. 2012; Li 2003, 2012). Recent research works reported that synthetic fibers could also be applied to UHPC instead of steel fibers. PE fibers made it possible to obtain a tensile ductility of $3 \%$ with compressive strength of $160 \mathrm{MPa}$ (Ranade et al. 2013). However, incorporating synthetic fibers only may deteriorate workability and enlarge crack width in UHPC even though it results in the improvement of tensile ductility (Kang et al. 2016). Further approaches to improve the properties of UHPC still need to be explored.

The fact that the durability of reinforced concrete is very closely related to crack width of concrete is well known (Lepech and Li 2009; Malumbela et al. 2010). The selfhealing performance of concrete is also dependent on crack 
width (Reinhardt and Jooss 2003). In a low water-binder ratio of concrete, such as in UHPC, control of crack width enables improvement of durability and self-healing performance. However, few studies about controlling the crack width of UHPC have been reported.

This study therefore aims to propose a reformed kind of UHPC which can exhibit high tensile ductility and controlled crack width simultaneously. For this purpose, fiber hybridization of steel fiber with a synthetic fiber is considered to improve ductility, and plastic beads are added into the material to control crack width under tensile loading. As mentioned earlier, partial replacement of steel fibers with high strength PE fibers can produce more ductile tensile behavior but cause enlarged crack width. Plastic beads were adopted to overcome this problem. The basic idea of this approach is as follows. Hydrophobic plastic beads incorporated in the UHPC acts as an artificial flaw because of imperfect bonding with the surrounding matrix, reducing first cracking strength and facilitating crack formation around the plastic beads (Wang and Li 2004). Well-dispersed plastic beads make it easy to induce multiple cracking, which can consequently reduce crack width. In this study, the mechanical performance and crack patterns of the proposed UHPC were investigated.

\section{Materials and Methods}

\subsection{Materials and Mixture Proportion}

Table 1 lists the mixture proportion of the UHPC matrix investigated in this study, which was designed for a target compressive strength of $150 \mathrm{MPa}$ when it is cured in the water at a temperature of $23{ }^{\circ} \mathrm{C}$ for 28 days. Portland Type I cement was used as the main binder and zirconia silica fume was used as supplementary cementitious material. Zirconia silica fume exhibits pozzolanic reaction, and fills the voids, which results in an increase in strength of the matrix.
Furthermore, it increases the packing density and introduces ball bearings between larger particles, which results in improvement of the flowability (Roussel 2011). The specific surface area and chemical composition of cement and zirconia silica fume are listed in Table 2. The chemical composition was measured using X-ray fluorescence (XRF). Pure silica composed of $99 \%$ silicon dioxide was adopted as a filler for the purpose of increasing strength and flowability. The average diameter of pure silica was $2.2 \mu \mathrm{m}$, which is between that of cement and zirconia silica fume. Therefore, it increases the packing density of the matrix, which results in an increase of strength and improvement of flowability (Roussel 2011). Silica sand with an average particle size of $500 \mu \mathrm{m}$ or less and a density of $2.62 \mathrm{~g} / \mathrm{cm}^{3}$ was used to maintain adequate composite stiffness and volume stability. Large aggregates, which can lead to higher matrix toughness and non-uniform fiber dispersion, were excluded from the mixture design (Chen and Liu 2004). Superplasticizer (SP) and anti-foamer were used to achieve proper rheological properties and to minimize the amount of air bubbles. An expansion admixture (EA) and shrinkage reducing admixture (SRA) were added to reduce shrinkage because of the high amount of binding materials used in UHPC. Hydrophobic polystyrene (PS) beads with angular shape and average size of $3.5 \mathrm{~mm}$ were used for making artificial flaws. Figure 1 shows the hydrophobic property and shape of PS beads. These beads have a very weak bond with a cementitious matrix, so they behave as an artificial flaw under tensile loading.

The fiber and PS beads contents for investigating their effects on the tensile behavior of UHPC are listed in Table 3. The M-S is a control mixture. Two types of steel fibers with lengths of 19.5 and $16.5 \mathrm{~mm}$ were used in the M-S mixture. The M-S-PB mixture contains PS beads at a volume fraction of $2.0 \%$. The M-PE is a UHPC in which steel fibers were replaced by $\mathrm{PE}$ fiber at a volume fraction of $33 \%$. The $\mathrm{M}-\mathrm{PE}-\mathrm{PB}$ is the same mixture as M-PE except that it

Table 1 Mix proportion of UHPC (weight ratio).

\begin{tabular}{c|c|c|c|c|c|c|c|c|c}
\hline Compound & \multicolumn{2}{|c|}{ Binder } & \multirow{2}{*}{$w / b$} & Filler & $\begin{array}{c}\text { Fine } \\
\text { aggregate }\end{array}$ & EA & SRA & SP & Anti-foamer \\
\cline { 2 - 10 } & Cement & $\begin{array}{c}\text { Zirconia } \\
\text { silica fume }\end{array}$ & & & & & & & \\
\hline \hline Proportion & 1 & 0.25 & 0.2 & 0.3 & 1.1 & 0.075 & 0.01 & $0.023-0.026$ & 0.0007 \\
\hline
\end{tabular}

Table 2 Specific surface and chemical composition of cement and zirconia silica fume.

\begin{tabular}{c|c|c|c|c|c|c|c|c|c|c|c}
\hline Material & Specific & \multicolumn{9}{c}{ Chemical composition } \\
\cline { 3 - 13 } & $\begin{array}{c}\text { surface } \\
\left(\mathrm{cm}^{2} / \mathrm{g}\right)^{\mathrm{a}}\end{array}$ & $\mathrm{SiO}_{2}$ & $\mathrm{Al}_{2} \mathrm{O}_{3}$ & $\mathrm{Fe}_{2} \mathrm{O}_{3}$ & $\mathrm{CaO}$ & $\mathrm{MgO}$ & $\mathrm{SO}_{3}$ & $\mathrm{TiO}_{2}$ & $\mathrm{~K}_{2} \mathrm{O}$ & $\mathrm{ZrO}_{2}$ & etc. \\
\hline \hline Cement & 3297 & 18.5 & 4.5 & 3.3 & 65.8 & 3.4 & 2.2 & 0.3 & 1.1 & - & 0.9 \\
\hline $\begin{array}{c}\text { Zirconia } \\
\text { silica } \\
\text { fume }\end{array}$ & 80,000 & 96.00 & 0.25 & 0.12 & 0.38 & 0.1 & - & - & - & 3.0 & 0.15 \\
\hline
\end{tabular}

\footnotetext{
${ }^{\mathrm{a}}$ Blaine for cement, BET nitrogen adsorption for zirconia silica fume.
} 


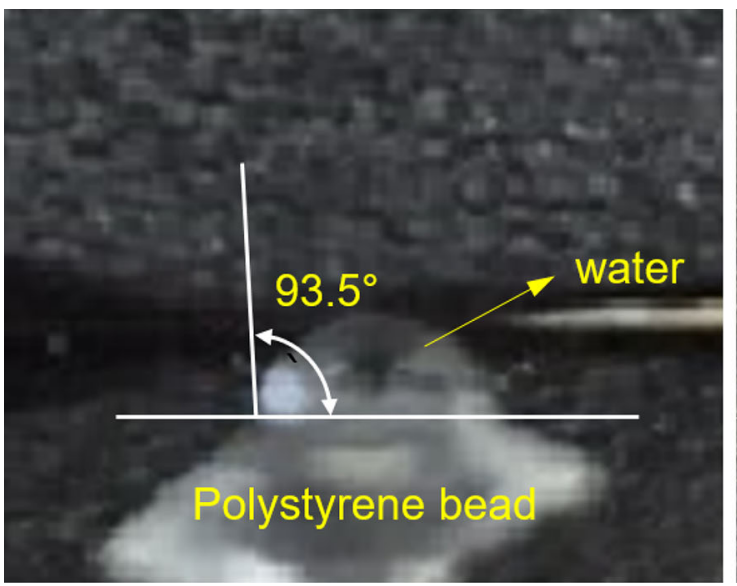

(a)

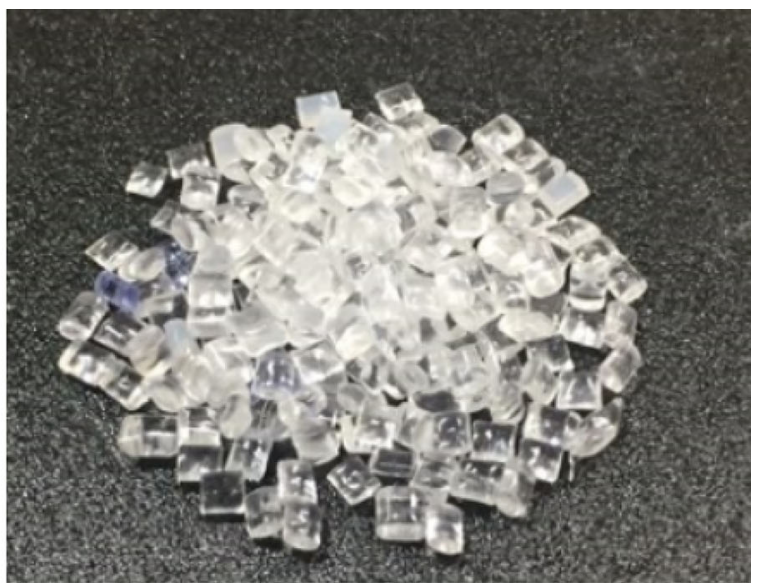

(b)

Fig. 1 PS bead: a hydrophobic surface, b Shape.

Table 3 Fibers and PS bead contents for UHPC.

\begin{tabular}{c|c|c|c|c}
\hline \multirow{2}{*}{ Mixture } & \multicolumn{3}{|c|}{ Fiber (vol\%) } & \multirow{2}{*}{ PS bead (vol\%) } \\
\cline { 2 - 5 } & Steel 19.5 & Steel 16.5 & PE \\
\hline \hline M-S & 1.0 & 0.5 & & 2.0 \\
\hline M-S-PB & 1.0 & 0.5 & 0.5 & \\
\hline M-PE & 0.67 & 0.33 & 0.5 & 2.0 \\
\hline M-PE-PB & 0.67 & 0.33 & & \\
\hline
\end{tabular}

Table 4 Properties of fibers.

\begin{tabular}{c|c|c|c|c|c}
\hline Type of fiber & Diameter $(\mu \mathrm{m})$ & Length $(\mathrm{mm})$ & Tensile strength $(\mathrm{MPa})$ & Density $\left(\mathrm{g} / \mathrm{cm}^{3}\right)$ & Elastic modulus $(\mathrm{GPa})$ \\
\hline \hline Steel & 200 & $16.3,19.5$ & 2500 & 7.8 & 200 \\
\hline PE & 12 & 18 & 2700 & 0.97 & 88 \\
\hline
\end{tabular}

contains PS beads. All mixtures have the same fiber contents at $1.5 \mathrm{vol} \%$. The shapes of cross-section of all fibers are round. The steel fibers used in this study were coated with brass. The dimensions of fibers as well as their physical and mechanical properties are listed in Table 4. Figure 2 shows the steel and PE fibers.

\subsection{Mixing, Casting, and Curing of Specimens}

Four types of mixtures were mixed using a Hobart type mixer. Firstly, cement, zirconium, filler, silica sand, EA, and SRA were placed into the mixer and mixed at a speed of $90 \mathrm{rpm}$ for $10 \mathrm{~min}$. Then liquid type ingredients, including water, SP, and anti-foamer were inserted into the mixer and

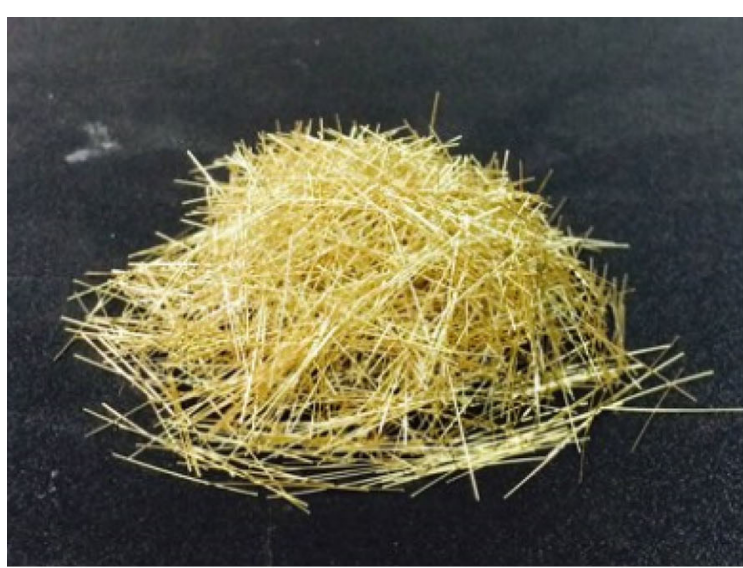

(a)

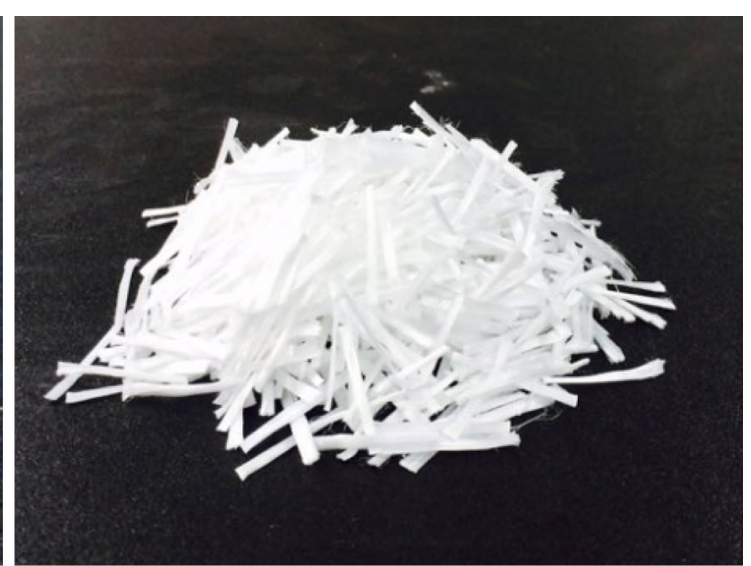

(b)

Fig. 2 Fibers; a steel fiber and b PE fiber. 
the mixture was mixed with the same speed for another about 4 min until the mixture changed into liquid form. When the mixture started to become flowable, the mixing speed was increased to $270 \mathrm{rpm}$, and then the mixture was mixed for a further $3 \mathrm{~min}$. The fibers or PS beads were then added into the mixer, and the mixture was mixed at a speed of $90 \mathrm{rpm}$ for another $5 \mathrm{~min}$. Lastly, the mixture was mixed for 1 more minute for the purpose of eliminating unwanted air voids. After mixing, each mixture batch was cast into cube-shape molds $\left(50 \times 50 \times 50 \mathrm{~mm}^{3}\right)$ for the compression test and dog-bone shape molds for the uniaxial tension test (conforming the recommendations of JSCE) (JSCE 2008). The molds were covered with plastic sheets and cured in a constant temperature room at a temperature of $23 \pm 3{ }^{\circ} \mathrm{C}$ for 3 days. The hardened specimens were then removed from the molds and cured in water until an age of 28 days in a constant temperature room at a temperature of $23 \pm 3{ }^{\circ} \mathrm{C}$.

\subsection{Hardened Density Test}

The hardened densities were measured to evaluate whether unintentional air bubbles were formed during the mixing process or not. The amount of air bubbles influences the strength of the matrix. The hardened densities were calculated by measuring their weight in air, $W_{A}$, and in water, $W_{W}$. The specimens were tested at 28 days in a water-saturated state with the excess water wiped from the surfaces:

$$
\rho=\frac{W_{\mathrm{A}}}{W_{\mathrm{A}}-W_{\mathrm{W}}} \times \rho_{\mathrm{W}}
$$

where $\rho$ and $\rho_{\mathrm{w}}$ are the densities of composite and water, respectively, and $\rho_{\mathrm{w}}$ is assumed to be $1 \mathrm{~g} / \mathrm{cm}^{3}$.

\subsection{Compressive Strength and Uniaxial Tension Tests}

The compressive strength of each specimen was measured according to ASTM C109-07 (ASTM 2007). The $50 \mathrm{~mm}$ cube specimen was used for the test and six specimens for each mixture were tested and average values and standard deviation on compressive strength were calculated. To investigate the behavior of the composites under tension, uniaxial tension tests were performed using an electronic universal testing machine according to JSCE recommendation (JSCE 2008). The tests were performed under displacement control with a loading speed of $0.1 \mathrm{~mm} / \mathrm{min}$; the loading force and elongation were measured. Two linear variable differential transducers were attached to both sides of the center of the tensile specimen with a gage length of $80 \mathrm{~mm}$ in order to monitor the elongation. The dimensions of the cross section within the gage length were $30 \mathrm{~mm} \times 30 \mathrm{~mm}$. In addition to the tensile stress-strain curves, crack patterns were observed. Five specimens for each mixture were tested and average values and standard deviation of tensile behavior were calculated.

\section{Results and Discussion}

\subsection{Hardened Density}

The average and standard deviation values of measured hardened densities for each mixture were listed in Table 5. As can be expected, the average values of hardened densities decreased by adding PS beads or PE fibers whose densities are much lower than those of other constituents. The error rate between measured densities and theoretical densities, which were calculated using the density of each composition and its proportion, is below $2.6 \%$. From these test results, it can be concluded that anti-foamer performed well for all specimens for each mixture which prepared by the manufacturing process described in Sect. 2.2. There is no sign of presence of any excessive amounts of entrapped air from the hardened density test results which is required for a proper UHPC.

\subsection{Compressive Strength}

The average and standard deviation values of compressive strength for each mixture were listed in Table 6. Figure 3 shows the relative compressive strength of each mixture. The average compressive strength of M-S-PB mixture was $3.6 \%$ lower than that of M-S mixture. This is attributed to the lower strength and elastic modulus of PS bead than the mortar of UHPC. The average compressive strength of M-PE mixture was $5.3 \%$ lower than that of M-S mixture. The average compressive strength of M-PE-PB mixture was $7.8 \%$ lower than M-S mixture, but the decrease in ratio of compressive strength was smaller than that of M-S-PB and M-PE mixtures. It can be concluded that negative effect of PE fiber and plastic bead addition on compressive strength is less that $10 \%$ for all tested mixtures.

\subsection{Uniaxial Tensile Performance}

Figure 4 shows the uniaxial tensile stress-strain curves of each mixture. All mixtures showed strain-hardening

Table 5 The measured and theoretical hardened density values of tested mixtures.

\begin{tabular}{c|c|c}
\hline \multirow{2}{*}{ Mixture ID } & \multicolumn{2}{|c}{ Density $\left(\mathrm{g} / \mathrm{cm}^{3}\right)$} \\
\cline { 2 - 3 } & Measured & Theoretical \\
\hline \hline M-S & $2.50 \pm 0.02$ & 2.44 \\
\hline M-S-PB & $2.48 \pm 0.02$ & 2.42 \\
\hline M-PE & $2.45 \pm 0.03$ & 2.38 \\
\hline M-PE-PB & $2.40 \pm 0.02$ & \\
\hline
\end{tabular}


Table 6 Compressive strength and standard deviation values of tested mixtures.

\begin{tabular}{c|c}
\hline Mixture ID & Compressive strength (MPa) \\
\hline \hline M-S & $146 \pm 2.1$ \\
\hline M-S-PB & $140 \pm 2.1$ \\
\hline M-PE & $138 \pm 1.2$ \\
\hline M-PE-PB & $134 \pm 3.3$ \\
\hline
\end{tabular}

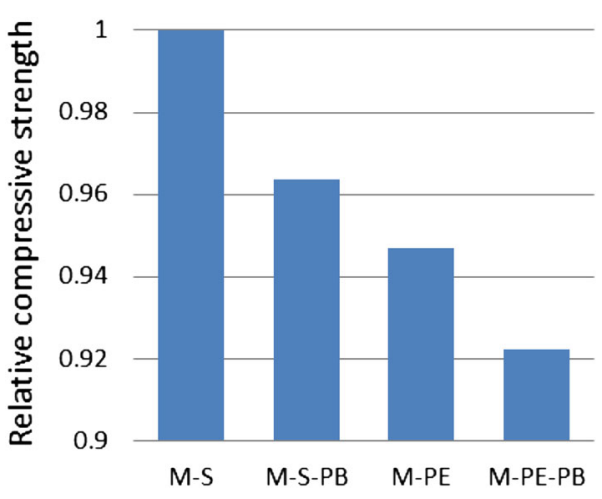

Fig. 3 Relative compressive strength of each mixture.

behavior under tension load after the first cracking. As compared with the M-S and M-S-PB mixtures, M-PE and M-PE-PB mixtures, which are reinforced with a fiber combination of steel fibers and PE fibers, showed a clearer stress

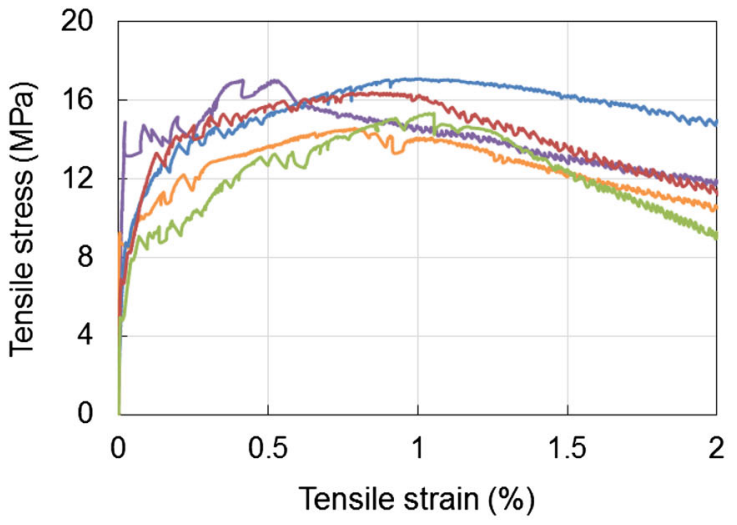

(a)

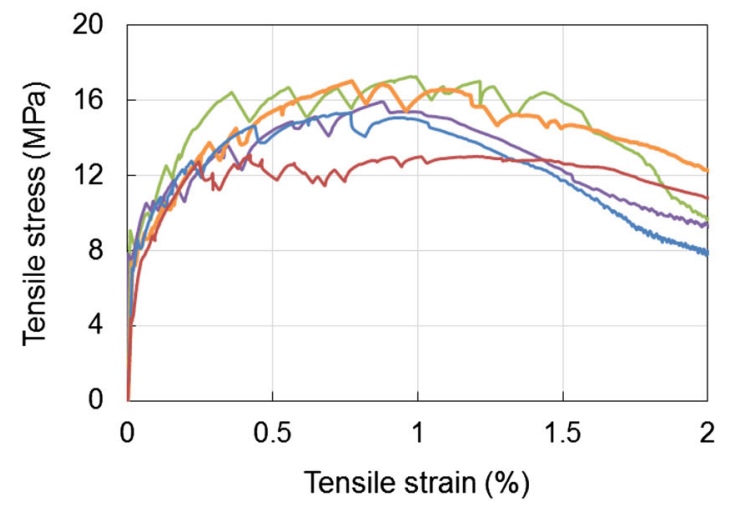

(c) drop at cracking and large tensile strain capacity. From these observations, it is found that the fiber bridging behavior is changed by the fiber hybridization, i.e., partial replacement of steel fiber by PE fiber resulted with larger crack opening. That means slippage between the fiber and the matrix requires the $\mathrm{PE}$ fiber to resist the load compared with steel fiber used in this study, which will be discussed with crack patterns. It was also observed that M-S-PB and M-PE-PB mixtures showed less stress drop at cracking than M-S and M-PE mixtures, respectively.

Figure 5 shows the first cracking strength of each mixture. Control mixture M-S showed the first cracking strength of 11.9 $\mathrm{MPa}$, and M-PE mixture showed the first cracking strength of 9.16 MPa. As expected, it was observed that the first cracking strength decreased with the addition of PS beads. M-S-PB and M-PE-PB mixtures showed 5.6\% and $8.7 \%$ lower first cracking strength than M-S and M-PE, respectively. M-PE mixture showed $22.9 \%$ lower first

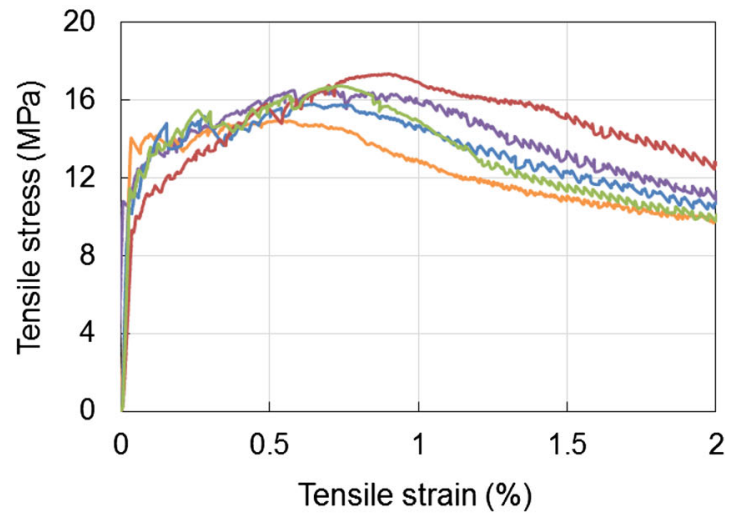

(b)

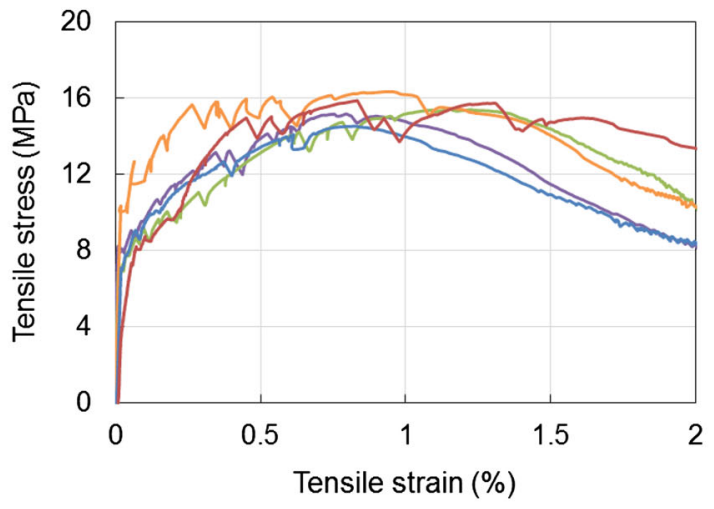

(d)

Fig. 4 Tensile stress versus strain curve of: a M-S, b M-S-PB, c M-PE, and d M-PE-PB. 


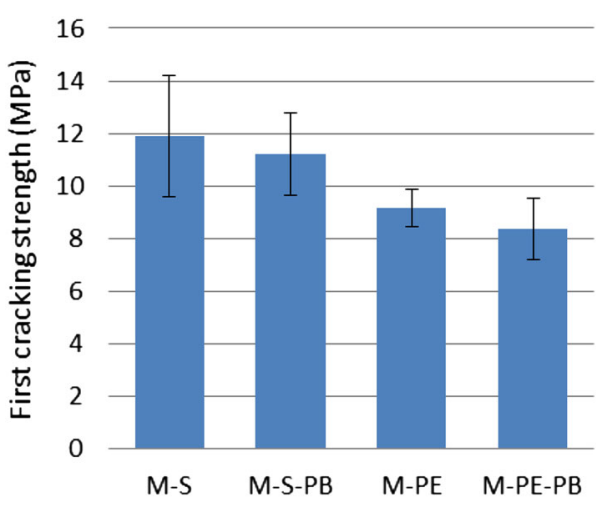

Fig. 5 First cracking strength of each mixture.

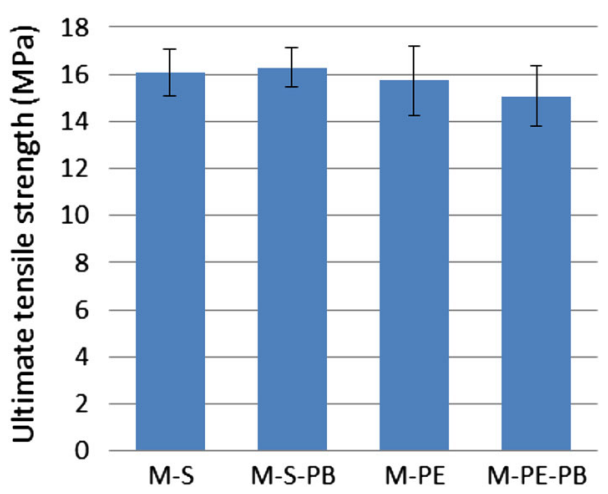

Fig. 6 Ultimate tensile strength of each mixture.

cracking strength than M-S mixture. The standard deviation of first cracking strength was decreased by the partial replacement of steel fiber with PE fiber and the addition of PS beads.

Figure 6 shows the ultimate tensile strength of each mixture. Control mixture M-S showed an ultimate tensile strength of 16.1 MPa. Although the first cracking strength of M-PE-PB mixture decreased up to $29.6 \%$ compared with the M-S mixture, the ultimate tensile strength of M-PE-PB mixture decreased only $6.3 \%$ compared with the M-S mixture. In particular, the M-PE mixture showed $2.2 \%$ lower ultimate tensile strength, which is much smaller than the decrease of the first cracking strength. The ratios of ultimate tensile strength to first cracking strength of M-S, M-S-PB, M-PE, and M-PE-PB mixtures were 1.4, 1.5, 1.7 and 1.8 , respectively. The potential of higher multiple cracking behavior increases with the higher ratio of ultimate tensile strength to first cracking strength (Kanda and $\mathrm{Li}$ 2006). It should also be noted that, ultimate tensile strength values were less affected by plastic bead addition and PE fiber usage compared to the compressive strength values reported in previous section which can be attributed to the enhanced multiple cracking behavior with these composite modifications.

Figure 7 shows the tensile strain capacity, which is defined as the strain corresponding to the ultimate tensile strength, of each mixture. Control mixture M-S showed the tensile strain capacity of $0.94 \%$. While M-PE and M-PE-PB mixtures showed 29.7 and $28.8 \%$ higher tensile strain capacity than

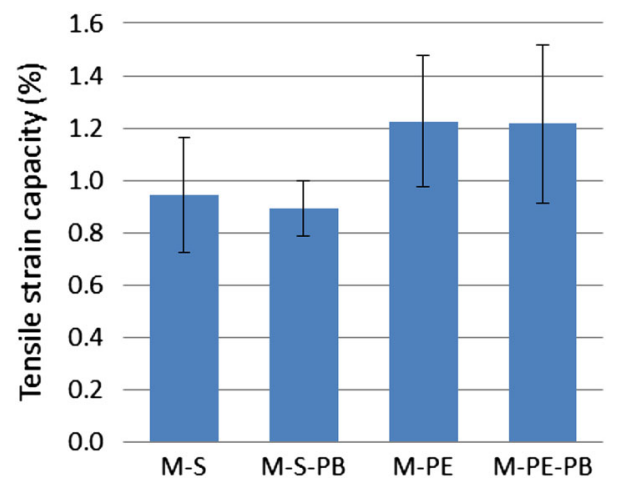

Fig. 7 Tensile strain capacity of each mixture.

M-S mixture, M-S-PB mixture showed $5.5 \%$ lower tensile strain capacity than M-S mixture. From these test results, it was found that the tensile strain capacity increased by the partial replacement of steel fiber with PE fiber, and that the PS beads used in this study slightly influenced the tensile strain capacity.

Figure 8 shows the crack patterns of representative specimens from each mixture. Multiple microcracks with a crack spacing of less than $7.7 \mathrm{~mm}$ were observed. Figures 9, 10 and 11 show the number of cracks, crack width, and crack spacing of each mixture. The number of cracks in the gage length $(80 \mathrm{~mm})$ were manually counted by using a microscope on both sides of each specimen. The crack width was calculated from the number of cracks and the deformation of the gauge length, during which it was assumed that all of the deformation occurred due to the opening of the crack caused by the relatively small deformation of the matrix after cracking. Crack spacings were calculated from the number of cracks and the gage lengths.

Control mixture M-S showed the number of cracks as 11.5, average crack width of $65.7 \mu \mathrm{m}$, and crack spacing of $7.7 \mathrm{~mm}$. M-S-PB mixture showed a $51.3 \%$ higher number of cracks, $37.5 \%$ smaller crack width, and $40.3 \%$ smaller crack spacing than M-S mixture. Although the ultimate tensile strength and tensile strain capacity were not improved by the addition of the PS beads used in this study, it was found that the number of cracks can be increased, and the crack width and crack spacing can be reduced, which may result in lower permeability and increased durability performance. In particular, it was observed that the standard deviations of the number of cracks, crack width, and crack spacing of the M-S-PB mixture remarkably decreased to $88.2,81.2$, and $96.2 \%$, respectively, which is quite different to the M-S mixture, meaning that uniform crack patterns can be achieved by the addition of PS beads.

The M-PE mixture showed a $15.2 \%$ higher number of cracks and $25.3 \%$ larger crack width than the M-S mixture. This is the main reason behind the higher tensile strain capacity of M-PE mixture over M-S mixture. The crack width is the same as the crack opening corresponding to maximum tensile stress, i.e., peak bridging stress, in the fiber bridging curves. Therefore, it can be concluded that crack opening corresponding to maximum tensile stress increases 


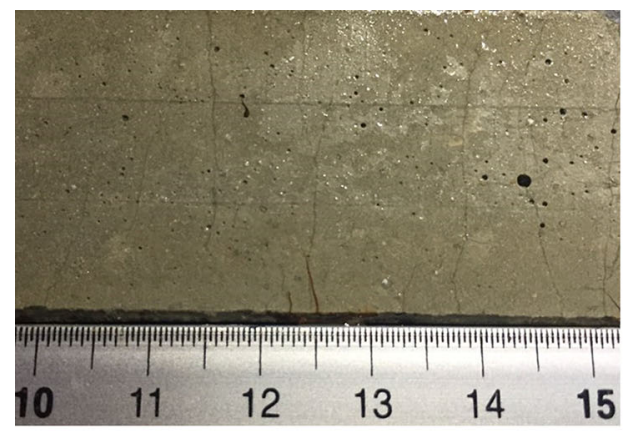

(a)

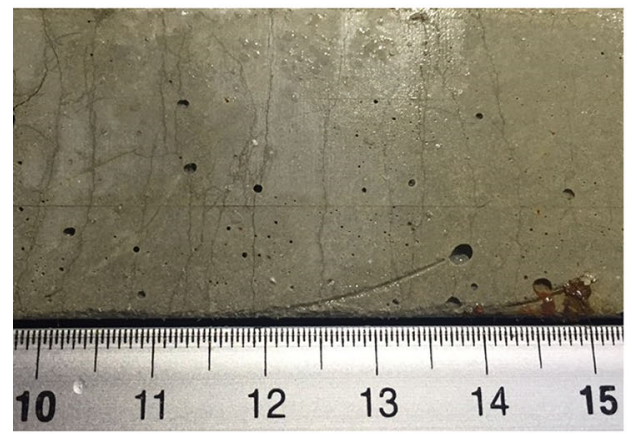

(b)

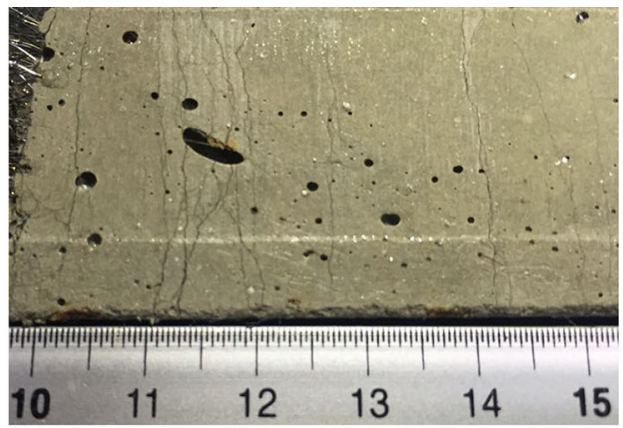

(c)

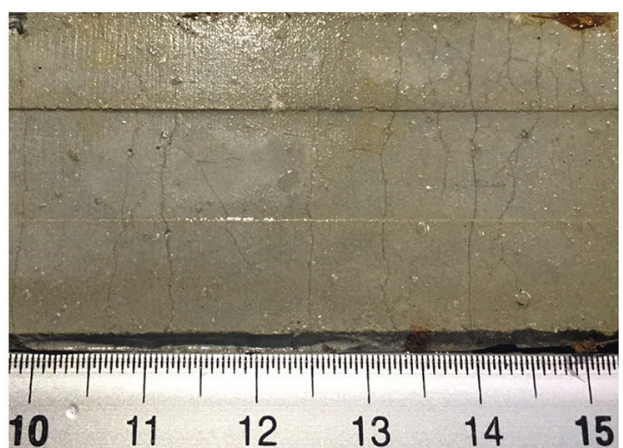

(d)

Fig. 8 Cracking pattern (unit of number: $\mathrm{cm}$ ). a M-S. b M-S-PB. c M-PE. d M-PE-PB.

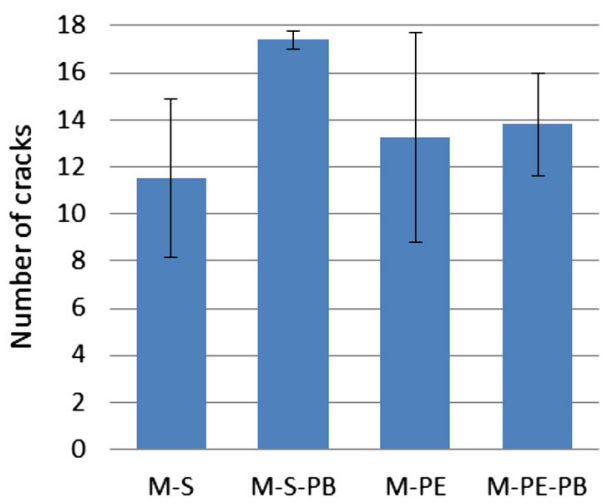

Fig. 9 Number of cracks of each mixture.

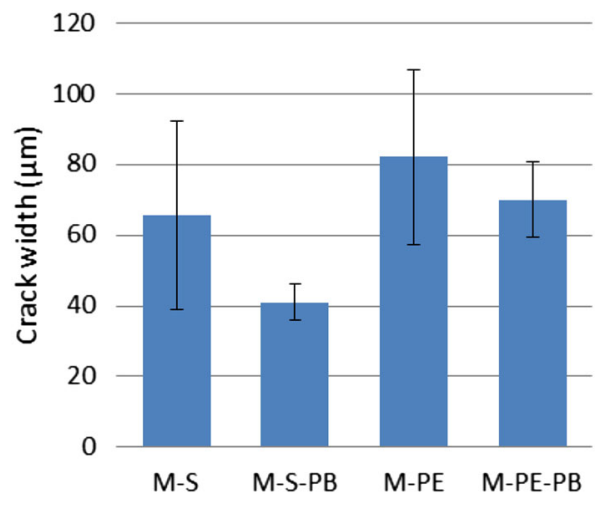

Fig. 10 Crack width of each mixture.

by the partial replacement of steel fiber with PE fiber. The standard deviation of M-PE increased slightly compared with M-S. M-PE-PB mixture showed a $4.2 \%$ higher number of cracks, $14.8 \%$ smaller crack width, and $16.4 \%$ smaller

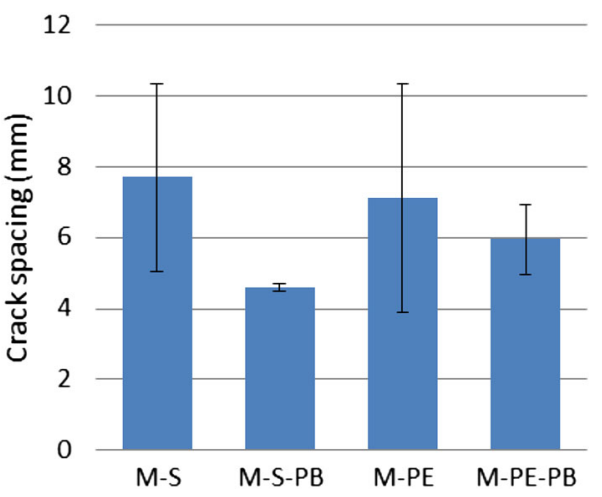

Fig. 11 Crack spacing of each mixture.

crack spacing than M-PE mixture. Although the effect of the addition of PS beads on the cracking pattern in hybrid steel and PE fiber reinforced UHPC decreased, the positive effect of the addition of PS beads on the cracking pattern was still valid and the standard deviation value was also decreased.

\section{Conclusions}

This study proposed a method to improve the tensile ductility and control crack width of UHPC and to examine the effect of artificial flaws and fiber hybridization on the tensile behavior of UHPC. A series of experimental tests including compression and uniaxial tension tests were performed and the different tensile behaviors and cracking patterns of each mixture were recorded and analyzed. The following conclusions can be drawn from the experimental results of this study. 
1. The ratios of ultimate tensile strength and first cracking strength of M-S, M-S-PB, M-PE, and M-PE-PB mixtures were $1.4,1.5,1.7$, and 1.8, respectively. From these observations, it was found that the potential for higher multiple cracking behavior can be increased by the partial replacement of steel fiber with PE fiber as well as with the addition of PS beads.

2. While M-PE and M-PE-PB mixtures showed 29.7 and $28.8 \%$ higher tensile strain capacity than M-S mixture, M-S-PB mixture showed $5.5 \%$ lower tensile strain capacity than M-S mixture. It was found that the tensile strain capacity increased by the partial replacement of steel fiber with PE fiber, and that the PS bead used in this study slightly influenced the tensile strain capacity.

3. While the ultimate tensile strength and tensile strain capacity were not improved by the addition of PS beads used in this study, it was found that the number of cracks can be increased and crack width and the crack spacing can be reduced. These cracking patterns have the potential of decreasing the permeability and hence increasing the durability performance.

4. The standard deviations of the number of cracks, crack width, and crack spacing of M-S-PB mixture, in which artificial flaws were formed by adding PS beads, decreased to $88.2,81.2$, and $96.2 \%$, respectively, which is quite different to M-S mixture without PS beads. These test results mean that more uniform crack patterns can be achieved by the addition of PS beads.

5. M-PE mixture showed a $15.2 \%$ higher number of cracks and $25.3 \%$ larger crack width than M-S mixture. From these observations, it can be concluded that the crack opening corresponding to maximum tensile stress increases by the partial replacement of steel fiber with PE fiber. The crack width and crack spacing of hybrid steel and PE fiber reinforced UHPC also decreased with the addition of PS beads. Overall, it was shown that the tensile behavior, including tensile strain capacity and cracking pattern of UHPC investigated in this study, can be controlled by the proper hybridization of steel and PE fibers in combination with the incorporation of artificial flaws into UHPC mixture.

\section{Acknowledgments}

This research was supported by a Grant (13SCIPA02) from Smart Civil Infrastructure Research Program and a Grant (15SCIP-B103706-01) from Construction Technology Research Program funded by Ministry of Land, Infrastructure and Transport (MOLIT) of Korea government and Korea Agency for Infrastructure Technology Advancement (KAIA).

\section{Open Access}

This article is distributed under the terms of the Creative Commons Attribution 4.0 International License (http://creativecommons.org/licenses/by/4.0/), which permits unrestricted use, distribution, and reproduction in any medium, provided you give appropriate credit to the original author(s) and the source, provide a link to the Creative Commons license, and indicate if changes were made.

\section{References}

AFGC. (2002). Ultra-high performance fibre-reinforced concrete-interim recommendations. Paris, France: Association Française de Génie Civil.

ASTM. (2007). Standard test method for compressive strength of hydraulic cement mortars (Using 2-in. or [50-mm] cube specimens): ASTM International West Conshohocken, PA.

Chen, B., \& Liu, J. (2004). Effect of aggregate on the fracture behavior of high strength concrete. Construction and Building Materials, 18(8), 585-590.

Choi, J.-I., Lee, B. Y., Ranade, R., Li, V. C., \& Lee, Y. (2016a). Ultra-high-ductile behavior of polyetylene fiber-reinforced alkali-activated slag-based composite. Cement and Concrete Composite, 70, 153-158.

Choi, J.-I., Song, K.-I., Song, J.-K., \& Lee, B. Y. (2016b). Composite properties of high-strength polyethylene fiberreinforced cement and cementless composites. Composite Structures, 138, 116-121.

Graybeal, B. (2011). Ultra-high performance concrete. Technote: FHWA-HRT-11-038, Federal Highway Administration, McLean, VA, 2013.

JSCE. (2008). Recommendations for design and construction of high performance fiber reinforced cement composites with multiple fine cracks (HPFRCC). Japan: Japan Society of Civil Engineers.

Kanda, T., \& Li, V. C. (2006). Practical design criteria for saturated pseudo strain hardening behavior in ECC. Journal of Advanced Concrete Technology, 4(1), 59-72.

Kang, S. T., Choi, J. I., Koh, K. T., Lee, K. S., \& Lee, B. Y. (2016). Hybrid effects of steel fiber and microfiber on the tensile behavior of ultra-high performance concrete. Composite Structures, 145, 37-42.

Lee, B. Y., Cho, C.-G., Lim, H.-J., Song, J.-K., Yang, K.-H., \& Li, V. C. (2012). Strain hardening fiber reinforced alkaliactivated mortar: A feasibility study. Construction and Building Materials, 37, 15-20.

Lepech, M. D., \& Li, V. C. (2009). Water permeability of engineered cementitious composites. Cement and Concrete Research, 31, 744-753.

Li, V. C. (2003). On engineered cementitious composites (ECC). Journal of Advanced Concrete Technology, 1(3), 215-230.

Li, V. C. (2012). Tailoring ECC for special attributes: A review. International Journal of Concrete Structures and Materials, 6(3), 135-144.

Malumbela, G., Alexander, M., \& Moyo, P. (2010). Interaction between corrosion crack width and steel loss in RC beams 
corroded under load. Cement and Concrete Research, 40, 1419-1428.

Ranade, R., Li, V. C., Stults, M. D., Heard, W. F., \& Rushing, T. S. (2013). Composite properties of high-strength, highductility concrete. ACI Materials Journal, 110(4), 413-422.

Reinhardt, H.-W., \& Jooss, M. (2003). Permeability and selfhealing of cracked concrete as a function of temperature and crack width. Cement and Concrete Research, 33(7), 981-985.

Richard, P., \& Cheyrezy, M. (1995). Composition of reactive powder concretes. Cement and Concrete Research, 25(7), 1501-1511.

Rokugo, K., Kanda, T., Yokota, H., \& Sakata, N. (2007). Outline of JSCE recommendation for design and construction of multiple fine cracking type fiber reinforced cementitious composite (HPFRCC). Paper presented at the proceedings, fifth international RILEM workshop on high performance fiber reinforced cement composites (HPFRCC 5).

Roussel, N. (2011). Understanding the rheology of concrete. Amsterdam, Netherlands: Elsevier.

Schmidt, M., \& Fehling, E. (2005). Ultra-high-performance concrete: Research, development and application in Europe. ACI Special Publication, 228, 51-78.

Stang, H., \& Li, V. C. (2004). Classification of fiber reinforced cementitious materials for structural applications. In Proceedings of the 6th International RILEM Symposium on Fibre-Reinforced Concretes (BEFIB'2004) (pp. 197-218).

Wang, S., \& Li, V. C. (2004). Tailoring of pre-existing flaws in ECC matrix for saturated strain hardening. Paper presented at the proceedings of FRAMCOS. 